\title{
Correction to: Mapping research in the field of private equity: a bibliometric analysis
}

\author{
Sakshi Sharma ${ }^{1} \cdot K_{\text {Knjana Malik }}^{2}$ D $\cdot$ Manmeet Kaur $^{3} \cdot$ Neha Saini $^{4}$
}

Accepted: 3 August 2021 / Published online: 9 August 2021

(c) The Author(s), under exclusive licence to Springer Nature Switzerland AG 2021

\section{Correction to: Management Review Quarterly https://doi.org/10.1007/s11301-021-00231-y}

The Funding information section was missing from this article and should have read 'Funding: Not applicable'.

The Conflict of Interest information section was missing from this article and should have read 'Conflict of Interest: The authors declare that they have no conflict of interest'.

Publisher's Note Springer Nature remains neutral with regard to jurisdictional claims in published maps and institutional affiliations.

The original article can be found online at https://doi.org/10.1007/s11301-021-00231-y.

Kunjana Malik

kunjanamalik.phd@fms.edu

Sakshi Sharma

sakshisharma.phd@fms.edu

Manmeet Kaur

manmeetkbawa@gmail.com

Neha Saini

neha.saini@nsut.ac.in

1 Atal Bihari Vajpayee School of Management and Entrepreneurship, Jawaharlal Nehru University, New Delhi, India

2 Vijay Patil School of Management, DY Patil University, Mumbai, India

3 Jindal Global Law School, O.P. Jindal Global University, Sonipat, Haryana, India

$4 \quad$ Netaji Subhas University of Technology, New Delhi, Dwarka, India 